\title{
Curar saberes difíciles. Arte y curaduría en contextos violentos: El caso Ayotzinapa
}

Artículo de reflexión

DOl: https://dx.doi.org/10.14483/udistrital.jour.c14.2017.1.a01

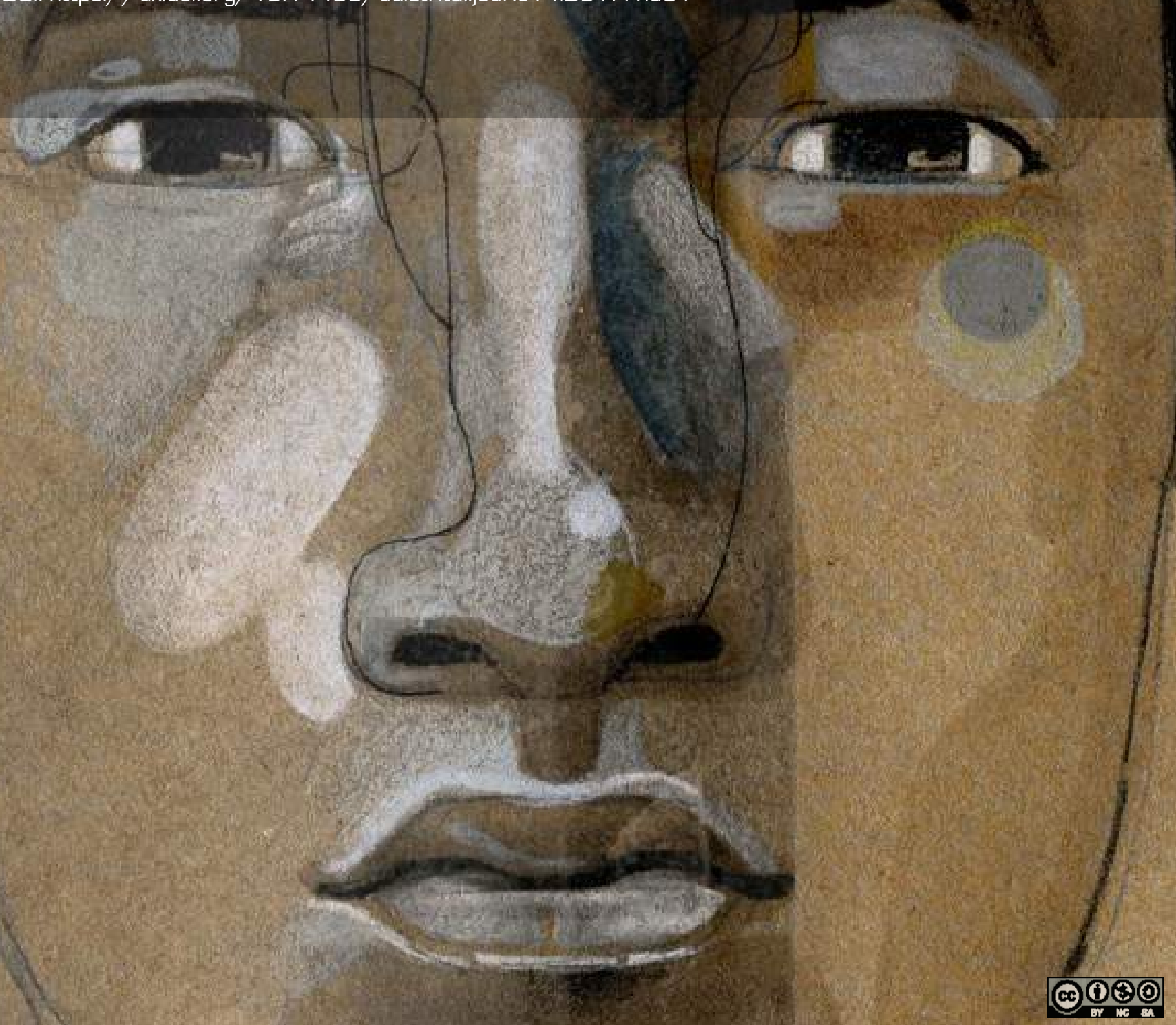

\section{Aurelio Meza}

Concordia University. / meza.aurelio@gmail.com

Magíster en Estudios Culturales del COLEF (Colegio de la Frontera Norte) Tijuana Baja California. Ph.D in Humanities. 
Meza, A [2017] Curar saberes difíciles. Arte y curaduría en contextos violentos: el caso Ayotzinapa. CALLE14: revista de investigación en el campo del arte, 12 [21], 14-29.

\title{
CURAR SABERES DIFÍCILES. ARTE Y CURADURIAA EN CONTEXTOS VIOLENTOS: EL CASO AYOTZINAPA
}

\begin{abstract}
RESUMEN
Bajo la premisa de conceptos como "saberes difíciles" y "sueño curatorial", de Erica Lehrer y otras académicas, este artículo documenta la curaduría de una exposición artística en torno a estudiantes de Ayotzinapa, México, muertos o desaparecidos en 2014. Debido en parte al seminario en que fue diseñado y en parte a circunstancias sociales en México y Canadá, este proyecto curatorial no se concretó. Sin embargo, este artículo propone analizar la distribución de conocimiento en torno a eventos pasados traumáticos y polémicos, así como acercarse a la curaduría como un proceso continuo sin final predeterminado. Incluye reflexiones con temas afines a Colombia y Québec [dos sociedades con las que el autor busca dialogar], como son el papel del arte en la resolución de conflictos sociales, la agencia de los movimientos estudiantiles y la defensa del derecho a disentir.
\end{abstract}

PALABRAS CLAVE

Curaduría; protesta; Ayotzinapa; México; estudiantes; saberes difíciles.

\section{AMBEI IACHAIKUNA MURUCHUKUNA, ARTE AMBIKUDIRURINA CONTEXTOKUNAPE UCHUIAKOKUNA: CHI AYOTZINAPA}

\begin{abstract}
MAILLALLACHISKA:
Urrai chi premisa chi conceptokuna chasa "iachaikuna murruchukuna" y "muskui ambiskasina" Erica Lehrerpa sug academicakuna, kai kilkaska nikome chi ambidirusina sug churaska artística iachaikudurkunamanda Ayotzinapamanda Mexicomanda wañuskakuna u chingariskakuna wata 2014 maillak debido seminariota karka allichiska mailla circunstancia socialkuna Mexicope y Canadape kai proyectok ambidirusina mana tukuchiska. Mana kagpek kai kilkaskak nekome kawangapa chi mingachii iachaikuna eventokuna ialeska traumatico y polemikokuna, chasa imasa kaillaiangapa ambirigkusinama sug proceso recheska mana tukurig predeterminado. iaikume iuiareikuna colombiamanda quebecmanda [iskai sociedadkuna chikunawa autorka maskanme Rimangapa] chasallata kakuna panga artemanda resolucionpe chi conflicto socialkuna. Chi agencia chi kuiurii iachaikudurkuna defenderei kai derecho disentingapa.
\end{abstract}

RIMANGAPA MINISTIDUKUNA:

Ambiakudirusina; protesta; ayotzinapa; Mexico iachaikugkuna; aichaikuna murruchukuna.

\section{CURING DIFFICULT KNOWLEDGE. ART AND CURATORIAL AT VIOLENT CONTEXTS: THE AYOTZINAPA CASE}

\begin{abstract}
Regarding concepts such as "difficult knowledge" and "curatorial dreams" by Erica Lehrer and other female academics, this article shows the artistic exposition of dead or disappeared students in Ayotzinapa, Mexico in 2014. This curatorial project was not totally completed due to two facts: the seminary in which it was designed, and social circumstances in Mexico and in Canada. Conversely, this article intends to analyze the distribution of knowledge around polemic and traumatic past events, as well as approaching curatorial as a continuous process having no predetermined ending. Some reflections on comparable to Colombian topics and Quebec Two unlike cultures that the author set into constant dialogue- as it is the role of art in socialconflict solving, the agency of student movements and the right to dissent defense.
\end{abstract}

\section{KEYWORDS}

Curatorial; protest; Ayotzinapa; Mexico; students; difficult knowledge. 


\title{
CONSERVATION DES SAVOIRS DIFFICILES. ART ET CONSERVATION EN DES CONTEXTES VIOLENTS : LE CAS AYOTZINAPA
}

\author{
RÉSUMÉ \\ Sous la prémisse de concepts tels que « connaissances difficiles » et « rêve de conservation \\ », par Erica Lehrer et d'autres chercheurs, cet article documente la conservation d'une \\ exposition d'art sur les étudiants d'Ayotzinapa, au Mexique, morts ou disparus en 2014. En \\ partie à cause du séminaire dans lequel il a été conçu et en partie aux circonstances sociales \\ au Mexique et au Canada, ce projet de conservation ne s'est pas concrétisé. Cependant, \\ cet article propose d'analyser la distribution des connaissances autour des événements \\ passés traumatisants et controversés, ainsi que d’aborder le travail du curateur en tant que \\ processus continu sans fin prédéterminée. Il s'y trouve des réflexions sur des questions liées à \\ la Colombie et au Québec [deux sociétés avec lesquelles l'auteur cherche le dialogue), comme \\ le rôle de l'art dans la résolution des conflits sociaux, l'action des mouvements d'étudiants et la \\ défense du droit à la dissidence.
}

\section{MOTS CLÉs}

Conservation; protestation; Ayotzinapa; Mexique; étudiants; connaissances difficiles.

\section{CURAR SABERES DIFÍCEIS. ARTE E CURADORIA EM CONTEXTOS VIOLENTOS: EL CASO AYOTZINAPA.}

\section{RESUMO}

Sob a premissa de conceitos como, "saberes difíciles" e "sueño curatorial", de Erica Lehrer e outras acadêmicas, este artigo documenta a curadoria de uma exposição artística em torno a estudantes de Ayotzinapa, México, mortos ou desparecidos em 2014. Devido em parte ao seminário em que foi desenhado e em parte a circunstâncias sociais no México e no Canadá, este projeto curatorial não se concretizou. Porem este artigo propõe analisar a distribuição de conhecimento em torno a eventos passados traumáticos e polêmicos, assim como aproximarse à curadoria como um processo contínuo sem final predeterminado. Inclui reflexões com temas afins a Colômbia e Québec [duas sociedades com as que o autor procura dialogar], como é o papel da arte na resolução dos conflitos sociais, a agência dos movimentos dos estudantes e da defesa do direito a dissidência.

\section{PALAVRAS-CHAVE}

Curadoria; protesto; Ayotzinapa; México; estudantes; saberes difíceis.

Recibido el 14 de septiembre de 2016 Aceptado el 18 de diciembre de 2016 
Yo, un ciudadano meXicano, de oficio ILUSTRADOR, HISTORIETISTA Y PINTOR, LE EXINOAL Estado Me diga dónde ESTÁ

Miguel Ãngel Hernández Martínez "EL BOTITA"

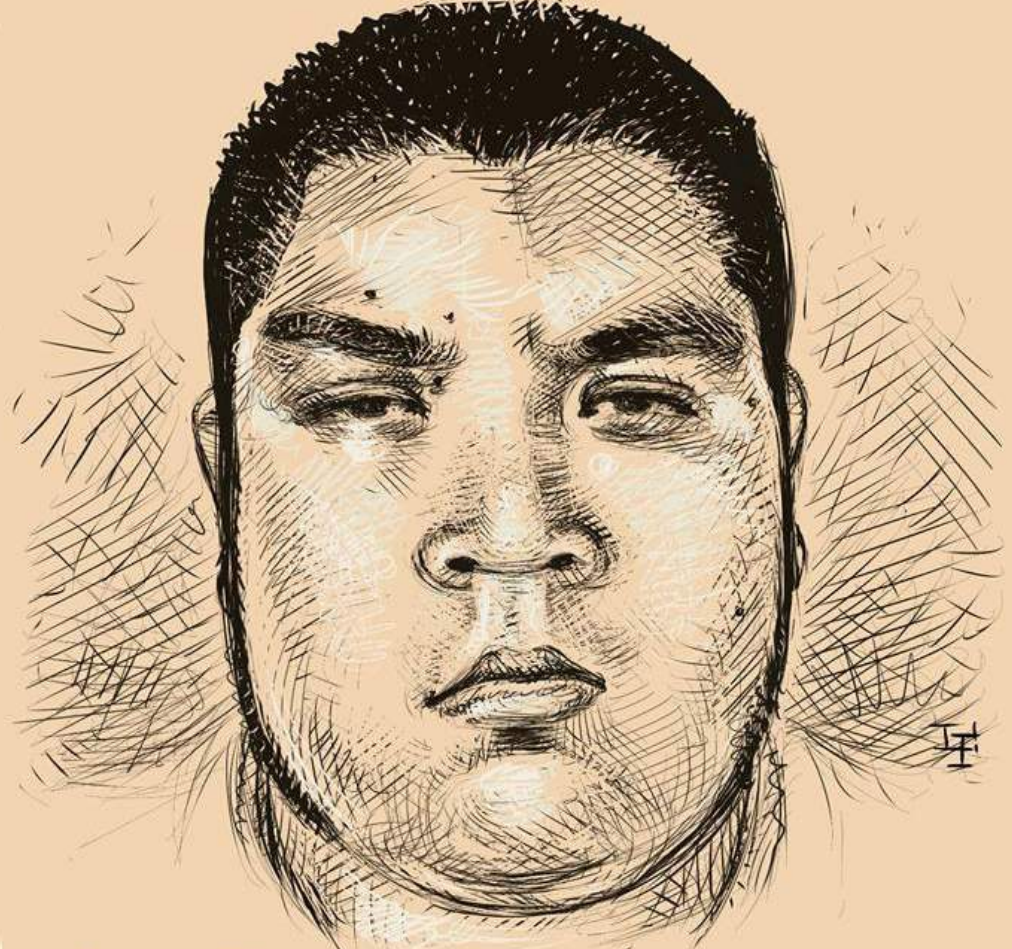

QUIERO VERLE A LOS OJOS Y ABRAZARLO, COMO HeRMANO MÍO QUE ES...

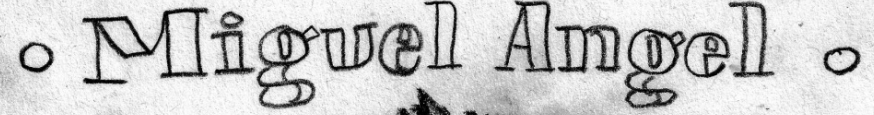
no habia entrado
a egtudiar antes of

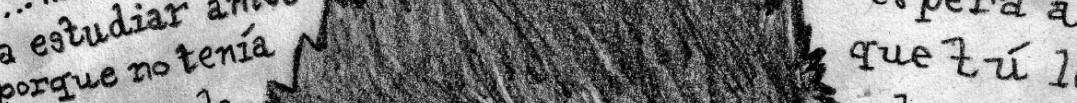
ieria, y se de-y dicaba mejor foll a ayudarle a sus papas, il es el más : thico, el los =uida $302, y$ thora no esta."

"..él apoya, ayuda, ze da consejos, él nurnca

\section{rerendora}

zes aloo él, al $\cos z z_{22 x i}$

\section{Jose}

ANGEL

NAVARRETE

GONZALE2

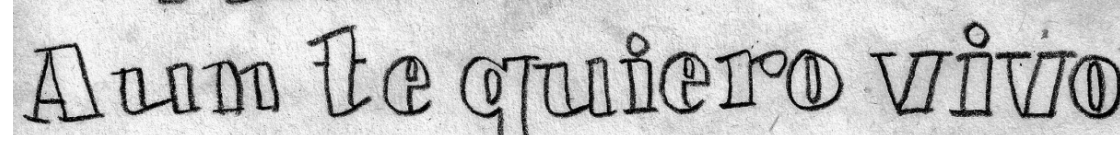

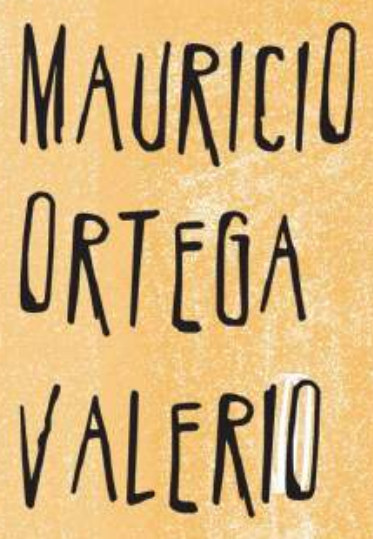


Aunque los curadores se enfrentan con múltiples problemáticas al tratar estos temas, Butler y Lehrer apuntan que

lo más 'difícil' del 'saber difícil' es su distribución desigual: el dolor causado por la historia y sus trazos no es compartido universalmente ni a través de límites grupales, ni uniformemente dentro de cada uno, ni a lo largo del tiempo, ya que los sentimientos cambian incluso dentro de los individuos [2016, pp. 20-21].

Una de las conclusiones más radicales a las que se llegó en ese seminario fue que curar temas difíciles puede abrir paso a una interpretación diametralmente opuesta a la nuestra, y a la pérdida total del control de la curadora sobre el mecanismo que esta misma ha puesto en marcha.

Uno de los objetivos del Seminario, basado en gran medida en los libros Curating Difficult Knowledge. Violent Pasts in Public Places [2006] y Curatorial Dreams: Critics Imagine Exhibitions [2016], era que cada participante realizara su propio "sueño curatorial”. Éste debía exhibir algún saber difícil, incluso si era imposible realizarlo, ya fuera por condiciones materiales o porque el conflicto en cuestión no estuviera oficialmente reconocido. Por lo reciente del tema, decidí concentrarme en la desaparición forzada de 43 estudiantes de la Escuela Normal Rural de Ayotzinapa, la noche del 26 de septiembre de 2014 , en el municipio mexicano de lguala, así como el asesinato de algunos compañeros suyos y varios desafortunados inocentes [Knoll y Wences, 2014]. Uno de los estudiantes asesinados fue Julio César Mondragón Fuentes; su cuerpo sin rostro fue encontrado al día siguiente por el Ejército, con claras muestras de tortura [Organización Editorial Mexicana, 2014; Pigeonutt, 2014). Una segunda autopsia, realizada dos años después, reveló 64 fracturas en 40 huesos, incluyendo el cráneo, el rostro y la columna, aunque la comisión encargada afirmaba que la piel de su rostro no fue arrancada por sus asesinos, como se había alegado, sino por animales carroñeros [Associated Press, 2016a]. Debió haber sufrido mucho durante sus últimos momentos de vida.

Las redes sociales contribuyeron a perseguir a los autores materiales e intelectuales, así como a obtener más evidencia de su corrupción. Varios medios han reportado la relación de alcaldes de la región con el narcotráfico [Red Política, 2014; Milenio Digital, 2014], así como la participación del Ejército en el traslado de los 43 desaparecidos (Mastrogiovanni, 2014). Sin embargo, no parece haber un cambio en la actitud de los políticos mexicanos, sino tan solo en el plano retórico. Funcionarios, como el entonces procurador general de la República, Jesús Murillo Karam, negaron la participación del Gobierno Federal, redujeron el problema al plano municipal y construyeron una "verdad histórica" que ha sido desmentida por numerosos especialistas [GIEI, 2015a; GIEl, 2015b; Reuters, 2015; Proceso, 2016].

Ya sea que tengan mala suerte o simplemente no sepan ser menos obvios, muchas afirmaciones que el presente Gobierno mexicano ha defendido como verdaderas se han colapsado paulatinamente. Hace unos meses, al promulgar unas leyes anticorrupción que luego fueron echadas para atrás por la

\section{¿DÓNDE ESTÁ?}
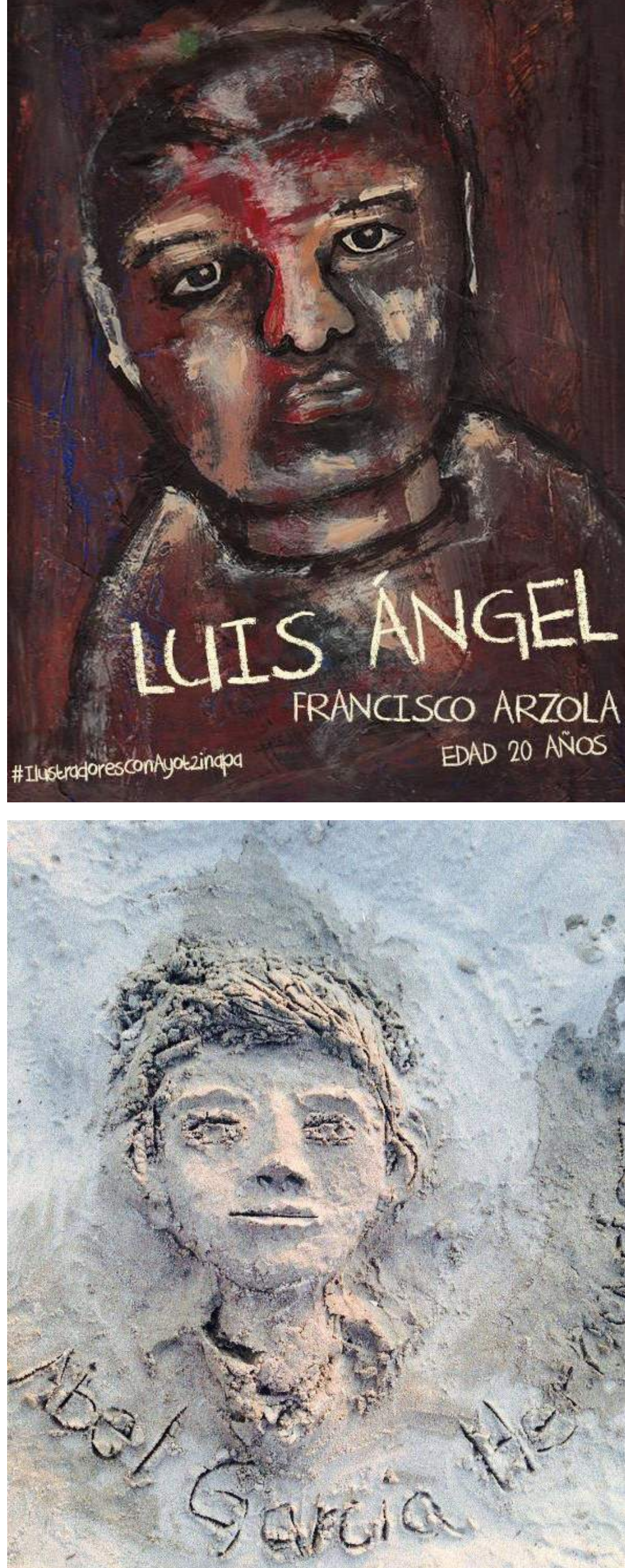

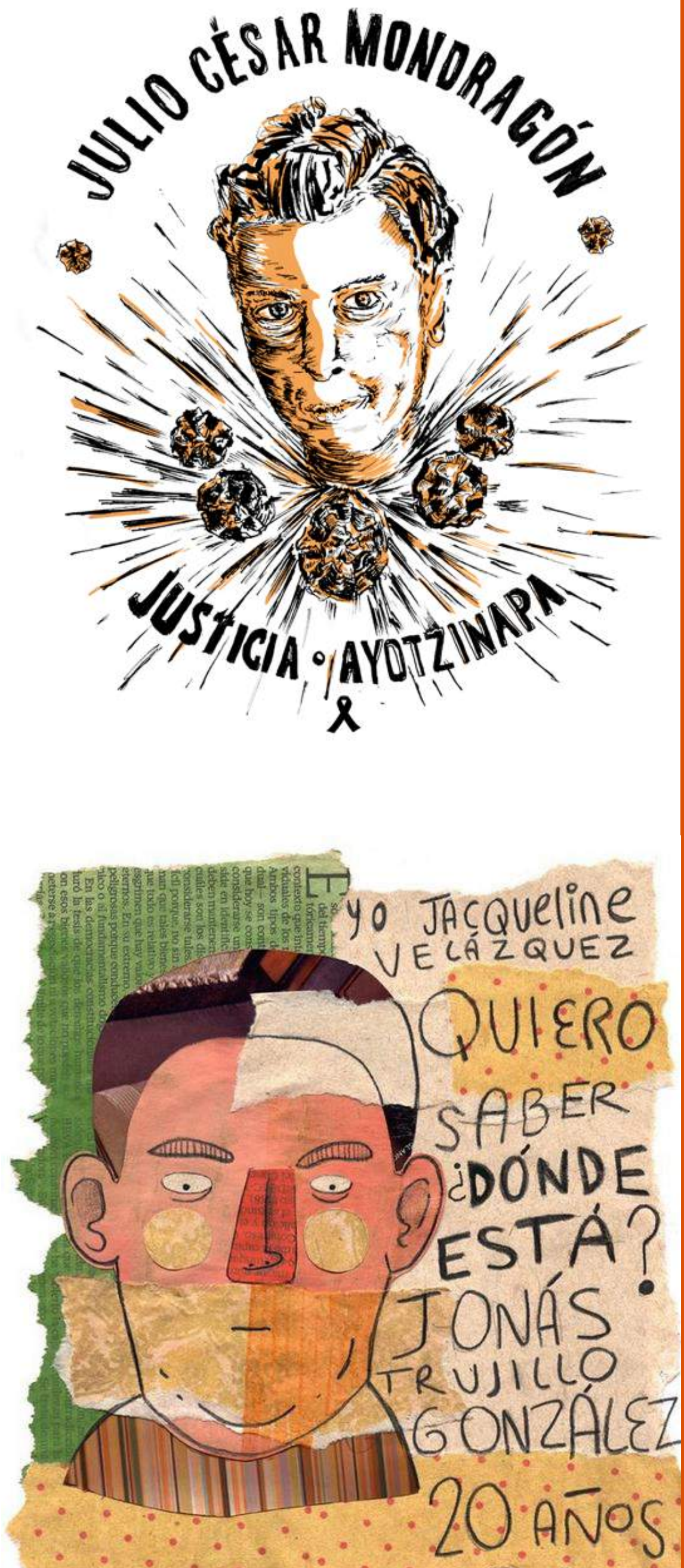

(2)

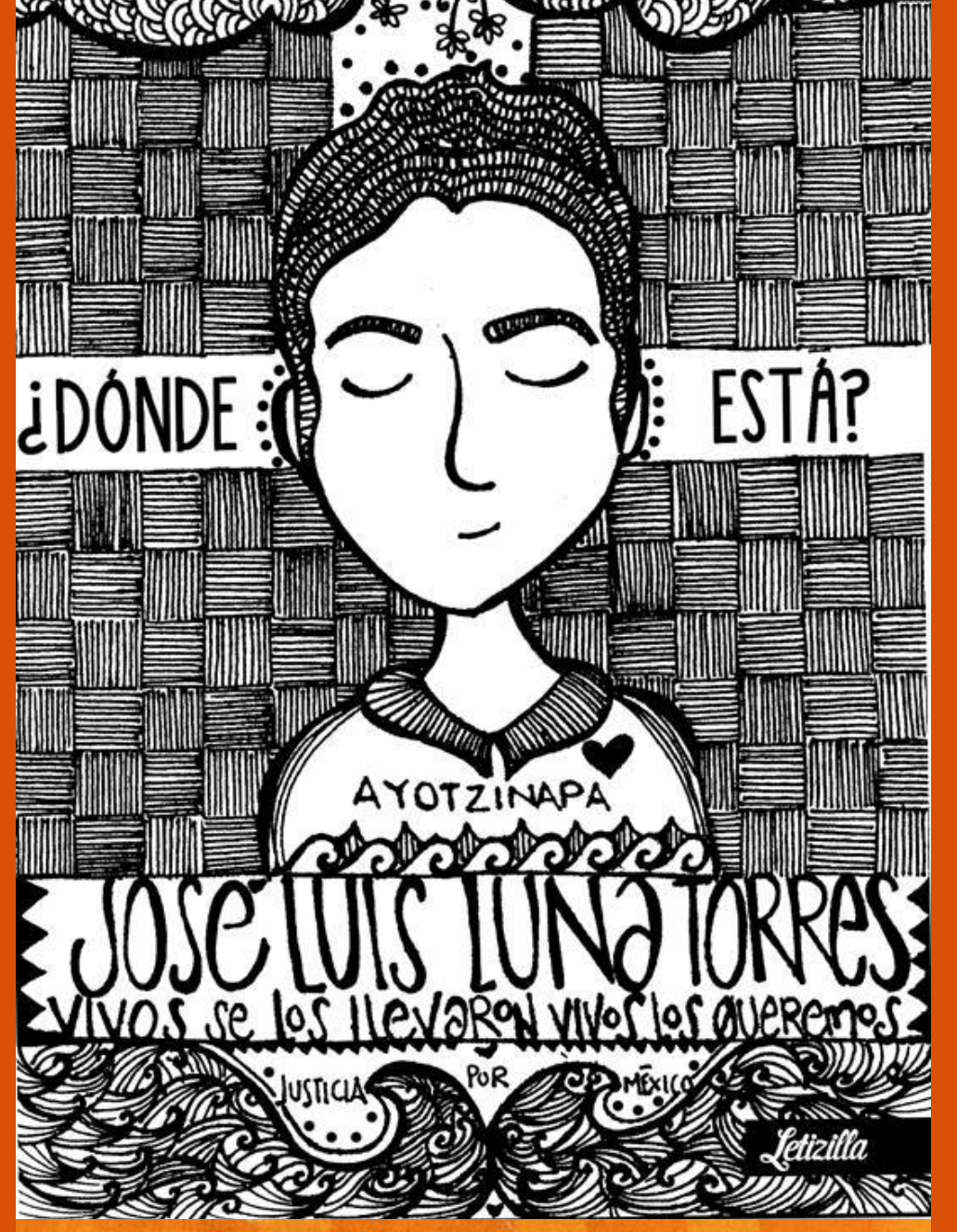

Uo, Huygo Vera,

Qunerer saben dolónde está?

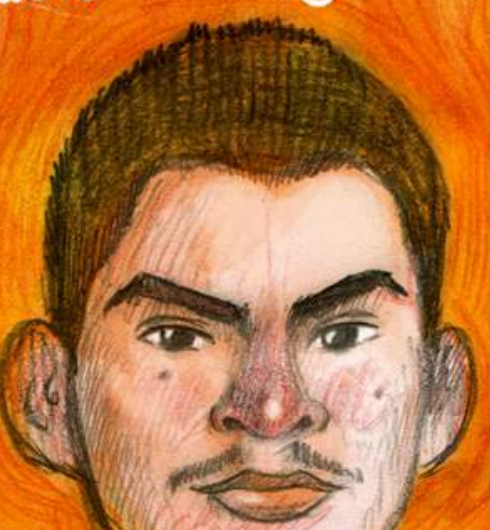


iniciativa privada, el presidente Enrique Peña Nieto se disculpó por el tema de la "Casa Blanca". Dicho escándalo implicaba un oscuro contrato inmobiliario con una empresa interesada en realizar proyectos con el Gobierno mexicano, el cual ofrecía a la familia presidencial una local conectada con otra a nombre de Angélica Rivera, la esposa de Peña Nieto. Pese a la disculpa, el presidente insistía en haber actuado bajo derecho, aunque reconocía que la situación había afectado la imagen presidencial [Animal Político, 2016a]. Pocos días después, el diario The Guardian publicó un reportaje sobre un departamento en Miami de Angélica Rivera, primera dama de México, cuya adquisición seguía un modus operandisimilar al de la "Casa Blanca" [Animal Político, 2016b; Ordaz, 2016; el artículo original fue removido]. Ante las circunstancias, la disculpa de Peña Nieto parece haber servido de poco para mejorar su imagen pública. Resulta todavía menos probable que lleguemos a escuchar una disculpa similar por Ayotzinapa y, más recientemente, por la muerte de maestros a manos de la Policía Federal en un enfrentamiento en Nochixtlán, Oaxaca (Najar, 2016; Associated Press, 2016b).

Antes de comenzar el Seminario de Lehrer expuse el tema de Ayotzinapa frente a estudiantes de la Maestría en Estudios Hispánicos de Concordia, principalmente colombianos y cubanos, quienes a su vez compartieron sus propios saberes difíciles. Sobre todo entre los casos colombiano y mexicano encontré paralelismos, aunque parece largo el trecho que México debe recorrer para llegar a una situación similar a la de Colombia hoy en día. Queda claro que la noción de "posconflicto" está lejos de expresar una realidad [representa más una intención que la descripción fiel de un proceso social], pero el simple reconocimiento de un conflicto está lejos de suceder en México. Pasará mucho tiempo antes que podamos siquiera concebir un discurso de reconocimiento parecido al del posconflicto colombiano. Es simplista pensar que en México estamos como los colombianos hace veinte años, pero ambos casos forman parte del desarrollo del necrocapitalismo en Latinoamérica, producto del enriquecimiento y el agenciamiento en el mercado capitalista global gracias al comercio de los cuerpos [Valencia, 2010].

Aunque al inicio del Seminario se estipuló que no habría una exhibición con los sueños curatoriales, el proceso motivó a Lehrer a proponer una exhibición al final del semestre, en el Centre for Ethnographic Research and Exhibition in the Aftermath of Violence [CEREV] de Concordia, que documentara los procesos curatoriales de cada participante. Los trabajos entrarían en diálogo unos con otros, tal y como durante las clases se suscitaron discusiones de las lecturas desde perspectivas y vivencias distintas.

En su forma más elemental, mi sueño curatorial buscaba documentar audiovisualmente las primeras reacciones artísticas en torno a Ayotzinapa. En el plano principal de la instalación, el público observaría un mosaico interactivo con los retratos que numerosos artistas visuales compartieron en redes sociales bajo el hashtag \#EscritoresConAyotzinapa, así como en diversos sitios web. Las imágenes cambiarían después de unos segundos, o bien el público podría navegar en las pantallas deslizando los retratos. Al calce de casi todos los retratos se observa la misma fórmula: "Yo [nombre del/la ilustrador/a] quiero saber dónde está [nombre del estudiante desaparecido]". Su ausencia y las "disciplinas del olvido" activadas por el Estado con su posición inamovible son de alguna manera subvertidas en la proliferación de rostros que ofrece \#llustradoresConAyotzinapa. Algunos de estos dibujos pueden llegar a ser ofensivos (como uno en el que la cabeza de un estudiante se derrama como si hubiera recibido un impacto de bala], pero todos buscan mantener su memoria viva y exigen mayor acción del Estado.

El despliegue visual estaría complementado por un reproductor de audio con una colección de paisajes sonoros de las marchas en solidaridad con Ayotzinapa. Mi instalación interactuaría con las de otros integrantes del sSminario de Lehrer interesados en la curaduría de sonidos [como Hubert Gendron-Blais y el movimiento de huelga estudiantil en Quebec, o el performance de Diego Gil sobre la plaza Tahrir en Egipto]. Por este motivo, los paisajes sonoros de mi instalación se escucharían a través de audífonos. La navegación visual y sonora permitiría al público involucrarse durante el tiempo que deseara, sin tener que ver ni escuchar la totalidad del material.

En otro juego de audífonos se podrían escuchar los poemas Ayotzinapa de David Huerta [Huerta, 2014; Rosales, 2014] y Mi país, joh mi país! de su padre, Efraín Huerta [2001]. En las versiones exhibidas, ambos poemas son leídos por el primero, lo que refuerza la impresión de que se trata de una serie de poemas del mismo autor. De hecho, la manera de leer del hijo es muy parecida a la del padre, aunque esta lectura de $M i$ país, joh mi país! es particularmente significativa porque, en los tres discos que grabó Efraín Huerta en vida, jamás incluyó este poema. Ambos son igualmente pertinentes para sus respectivas épocas. "Mi país, joh mi país!", publicado en 1959, ya vislumbraba la guerra sucia en versos cuyo eco resuenan con eventos históricos futuros, como la matanza de Tlatelolco de 1968 y el "Halconazo" de 1971, dirigidos principalmente contra estudiantes:

Un niño que interroga parece un niño muerto. Luego la madre pregunta por su hijo y la respuesta es un mandato de aprehensión [Huerta, 2001]

Ayotzinapa fue escrito y publicado poco después del incidente. Aunque primero tiene un tono similar al de su padre (no del todo político aunque claramente de denuncia], su conclusión es pasmosa:

\section{Ahora mejor callarse \\ Hermanos \\ Y abrir las manos y la mente \\ Para poder recoger del suelo maldito \\ Los corazones despedazados [Rosales, 2014].}

Aquí reaparece el tópico del poeta que, frente a la masacre, elige el silencio. Una de sus encarnaciones más mediáticas proviene de Javier Sicilia y su acto de abandonar la poesía luego de la muerte de su hijo, a manos del crimen organizado [E] Universal, 2013]. La desaparición de la figura del poeta significó el nacimiento de la figura pública, portavoz [no autorizado pero muy mediatizado] de familiares de las víctimas de la guerra 


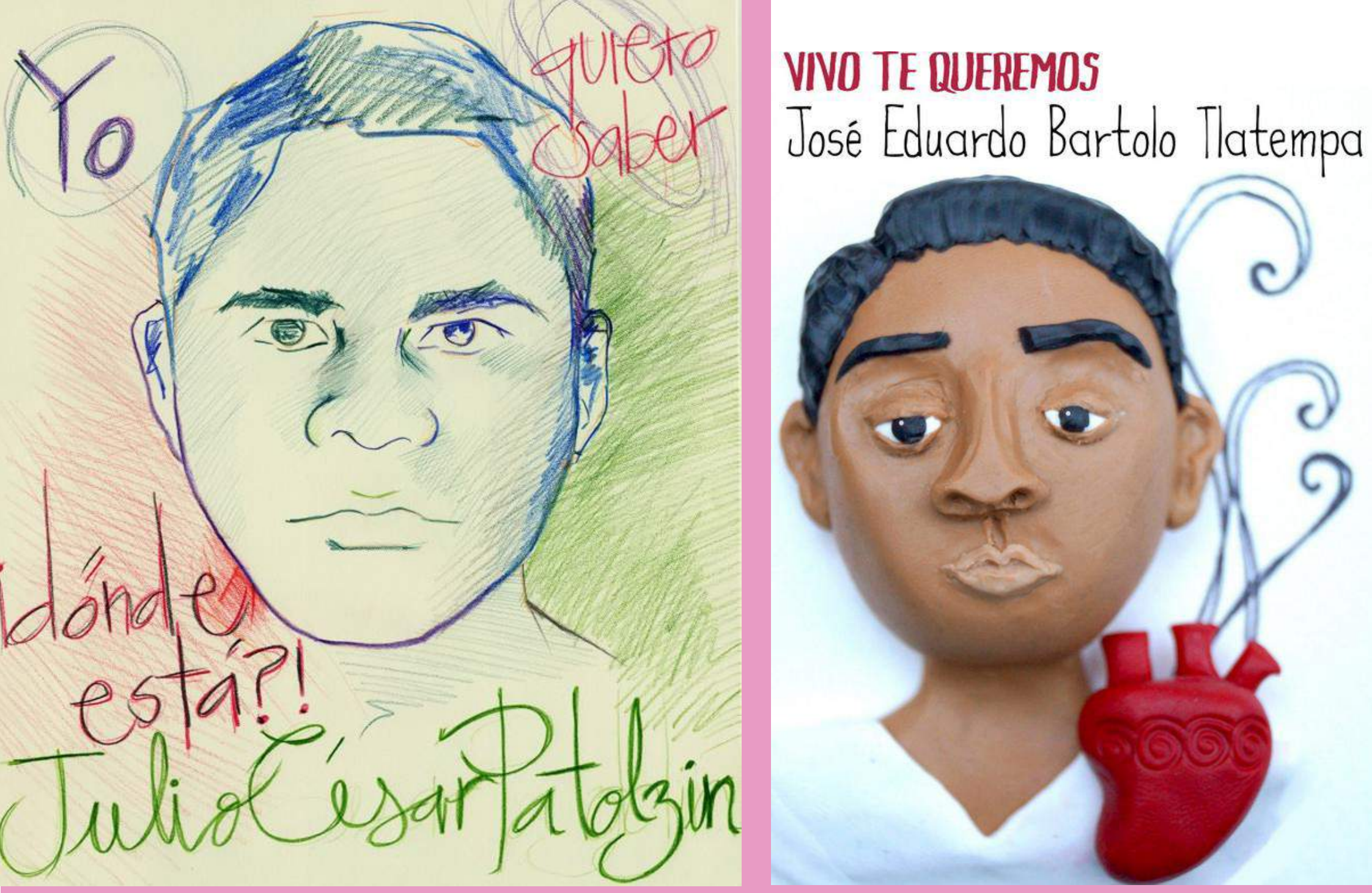

flujo de activismo artístico que buscaba mostrar. También estuvo acompañada de una mesa redonda, Categorías y construcciones sociales en épocas de violencia, que trató los casos de Colombia, México y Perú [CEREV, 2014]. El antecedente de la curaduría de Carton de Grammont, tan reciente y completo, lo volvió en retrospectiva otra parte integral de mi sueño curatorial.

La llegada de una huelga estudiantil en Concordia a finales de invierno, en mayo de 2015, interrumpió el proceso curatorial. Ante la efervescencia política, la más grande en Quebec desde el movimiento estudiantil de 2012 [conocido como "La primavera de maple"], este sueño curatorial enfocado en un grupo muy vulnerable de estudiantes en México [las escuelas normales rurales] podría haber contribuido a un diálogo sobre los movimientos estudiantiles, la agencia social y el derecho a disentir en Norte y Latinoamérica. Los estudiantes en Quebec han tenido históricamente un alto impacto político en su sociedad, ya que si las colegiaturas en la provincia se encuentran entre las más bajas de Norteamérica se debe en gran medida a la historia de protestas estudiantiles posteriores a 1968, los movimientos antirracistas y los grupos prosoberanos. ¿Qué podrían, entonces, aprender los estudiantes de Quebec de la historia de los 43 desaparecidos? Primero que nada, que las estrategias típicamente usadas en los movimientos de protesta [huelgas, bloqueos, manifestaciones] no resultan necesariamente en transformaciones reales y concretas en la Realpolitik. Esto no significa que el derecho a disentir no deba ser defendido a toda costa, sobre todo frente a la posible disipación de la agencia estudiantil por cambios globales mayores, como los programas neoliberales de austeridad económica o el calentamiento global. Segundo, al observar cómo las protestas estudiantiles son tratadas de formas similares en México y Quebec, ayuda a observar que las estrategias neocoloniales, que antes se aplicaban solo a excolonias o países en desarrollo, ahora se aplican también dentro de las naciones desarrolladas.

Debido a los propios flujos sociales y emocionales del movimiento estudiantil en el que me encontraba inmerso, mi sueño curatorial siguió siendo solo un proyecto. Durante este reposo obligatorio me he dado cuenta que no quería "crear" una obra nueva con el tema de Ayotzinapa, sino canalizar las miradas críticas hacia otros artistas que estuvieran creando arte en el momento de la confusión y el dolor. Es común preguntarse en la curaduría de temas difíciles sobre la responsabilidad curatorial para con los temas tratados:

¿Qué le debemos a las víctimas?, ¿cómo podemos transmitir mejor sus historias sin apropiarlas, sin llamar innecesariamente la atención a nosotros, y sin tampoco ver nuestras historias desplazadas por ellas?, ¿cómo estamos implicados en estos crímenes?, ¿la memoria del genocidio puede transformarse en acción y resistencia? (Hirsch, 2008, p. 104). 
Aba garcia Hormandez, Abelardo Vogquez Periten - Adan Abraján de la Cro Alexander Mora Venancio - Antonio Santana Maestro- Benjamín Ascencic Coutista. Caxlos Iván Ramirez, Villarreal-Carlos Lorenzo Homándeg Muîx Chrstian Tomás gonzález Hernández. Christian Alfonso gutierrez Telumk Emiliano Alen grepar de la Gumica. Cutberto Ortiz Ramos. Donan gonjólez Am Everardo Rodriguez Belo- Febp Galindes guerrero-Israel

Jovany Rodrigueg Tala

Alowg Mawa- Jorge

Mlome Tana logit bo

honge campos oand

jon Ebredo ent

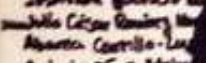

Momis of

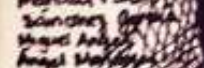
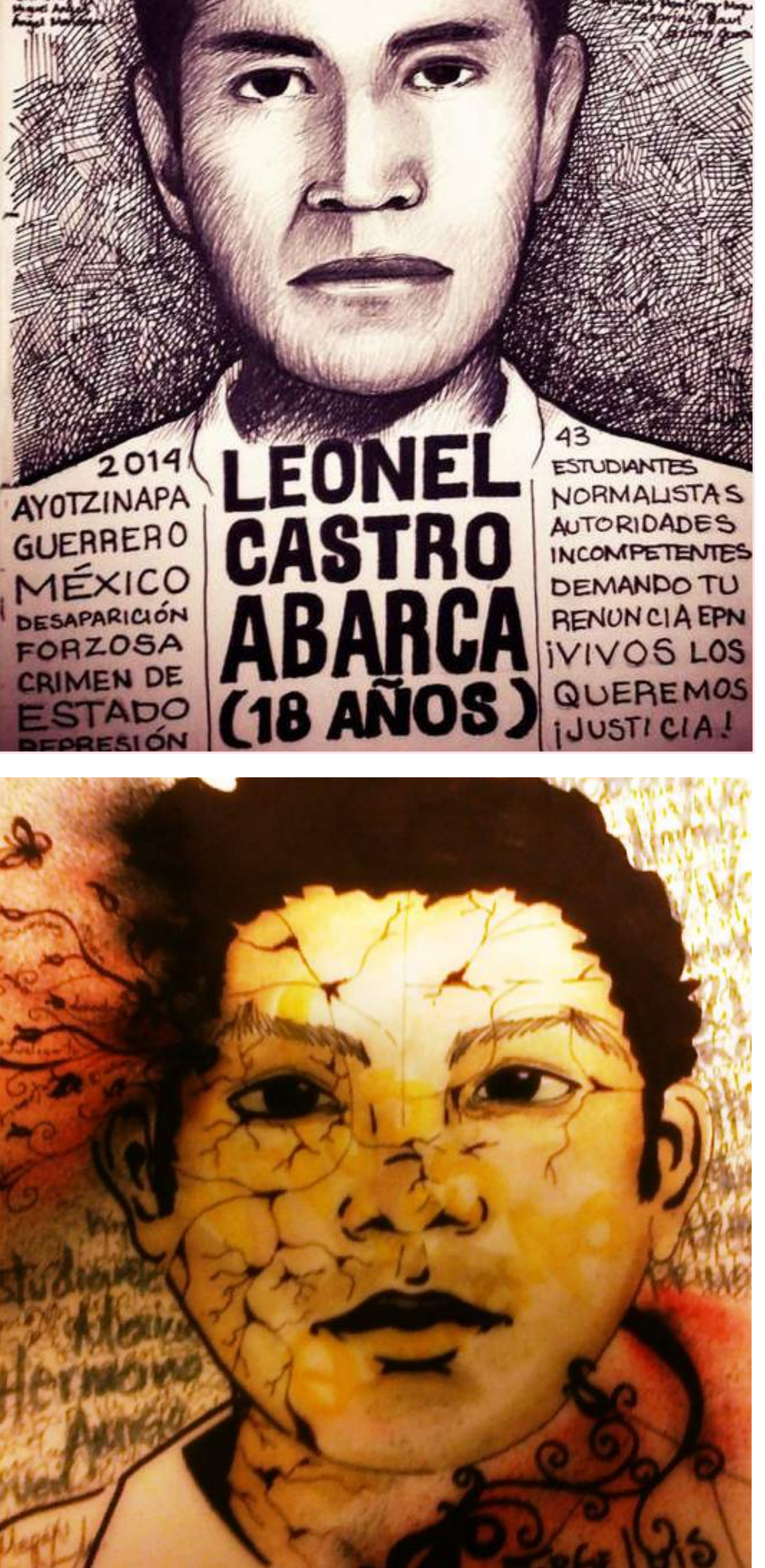

Y, BEF, QUIERO SABER DONDE ESTA' BERNARDO FLORES ALCARA'

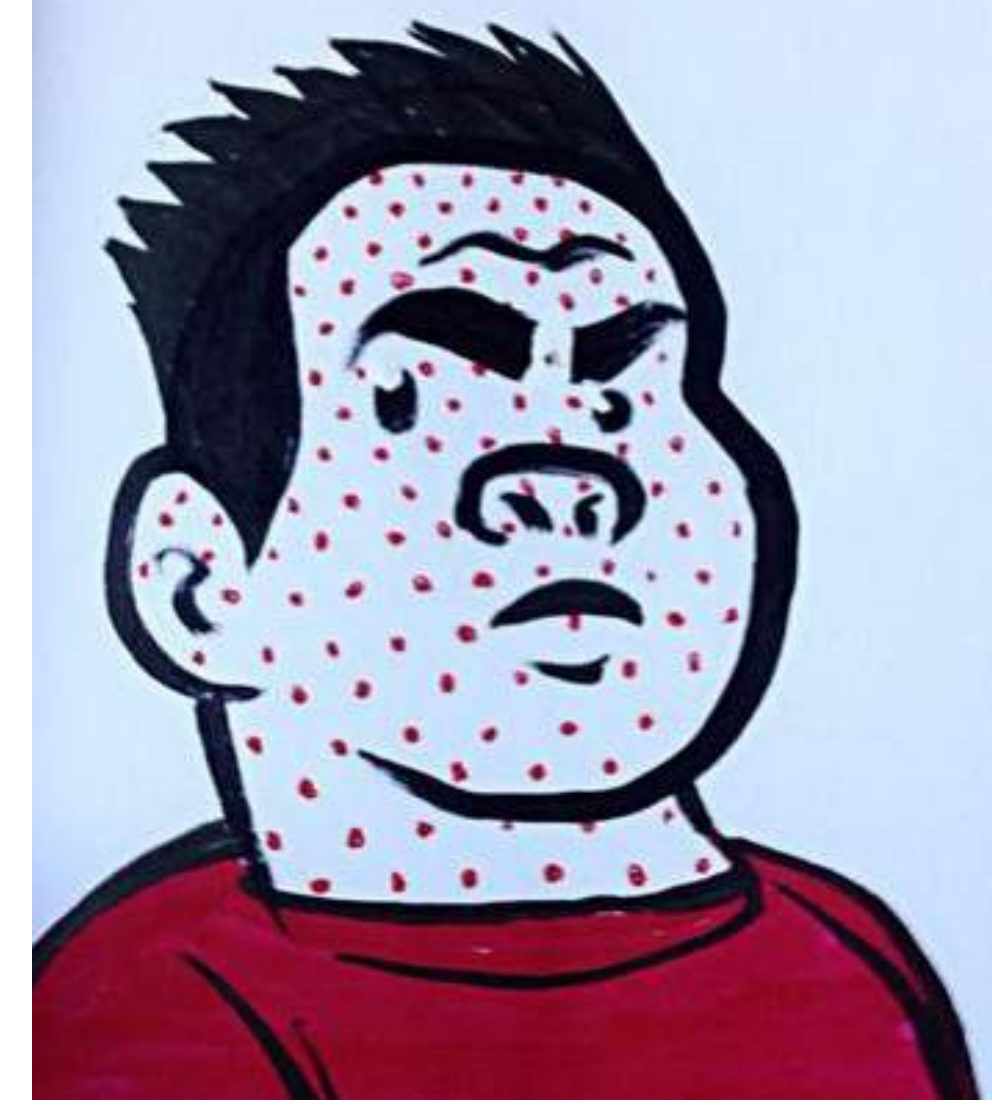

Yo Cecilia Cola, quiero saber dónde está a. 9

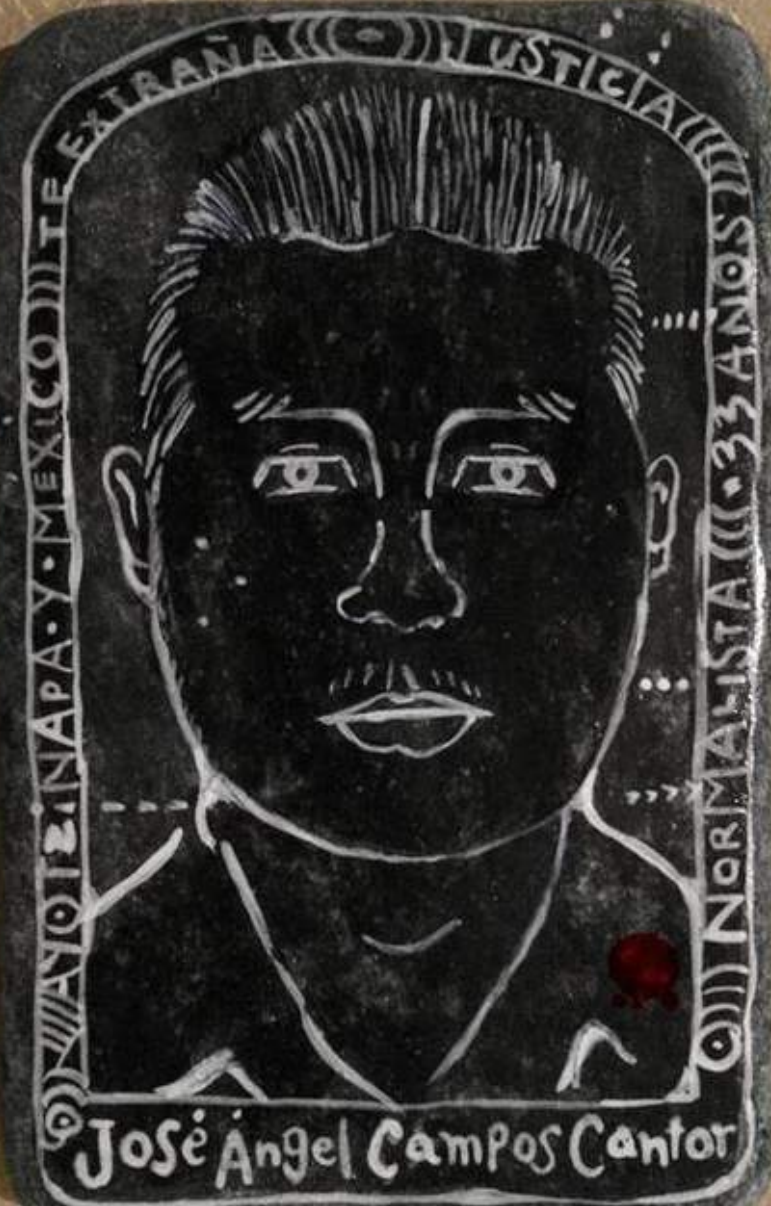




\section{¿DONDE ESTA?}
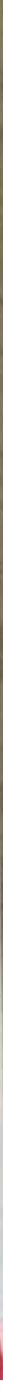

LODWE ESTAR

(6) a $1 \mathrm{c}$

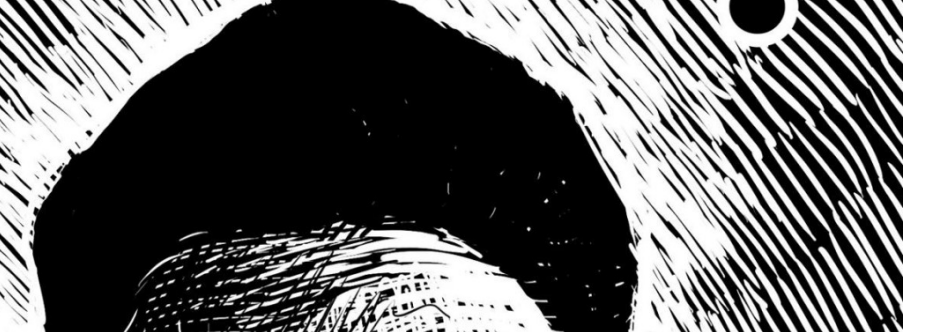
mos (r)

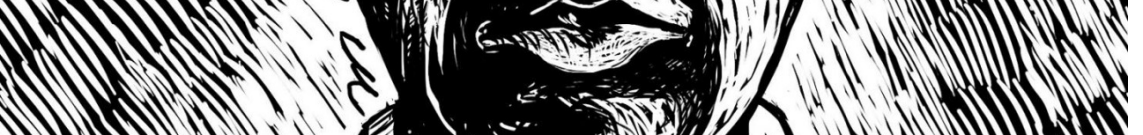
1.1.

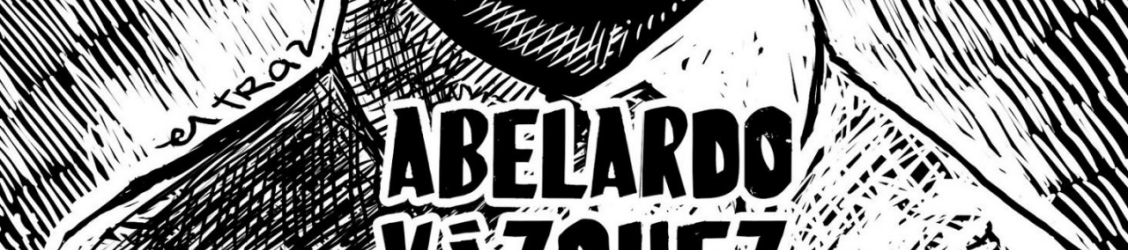
TOZOUEL
PENITEN 20 AÑOS 


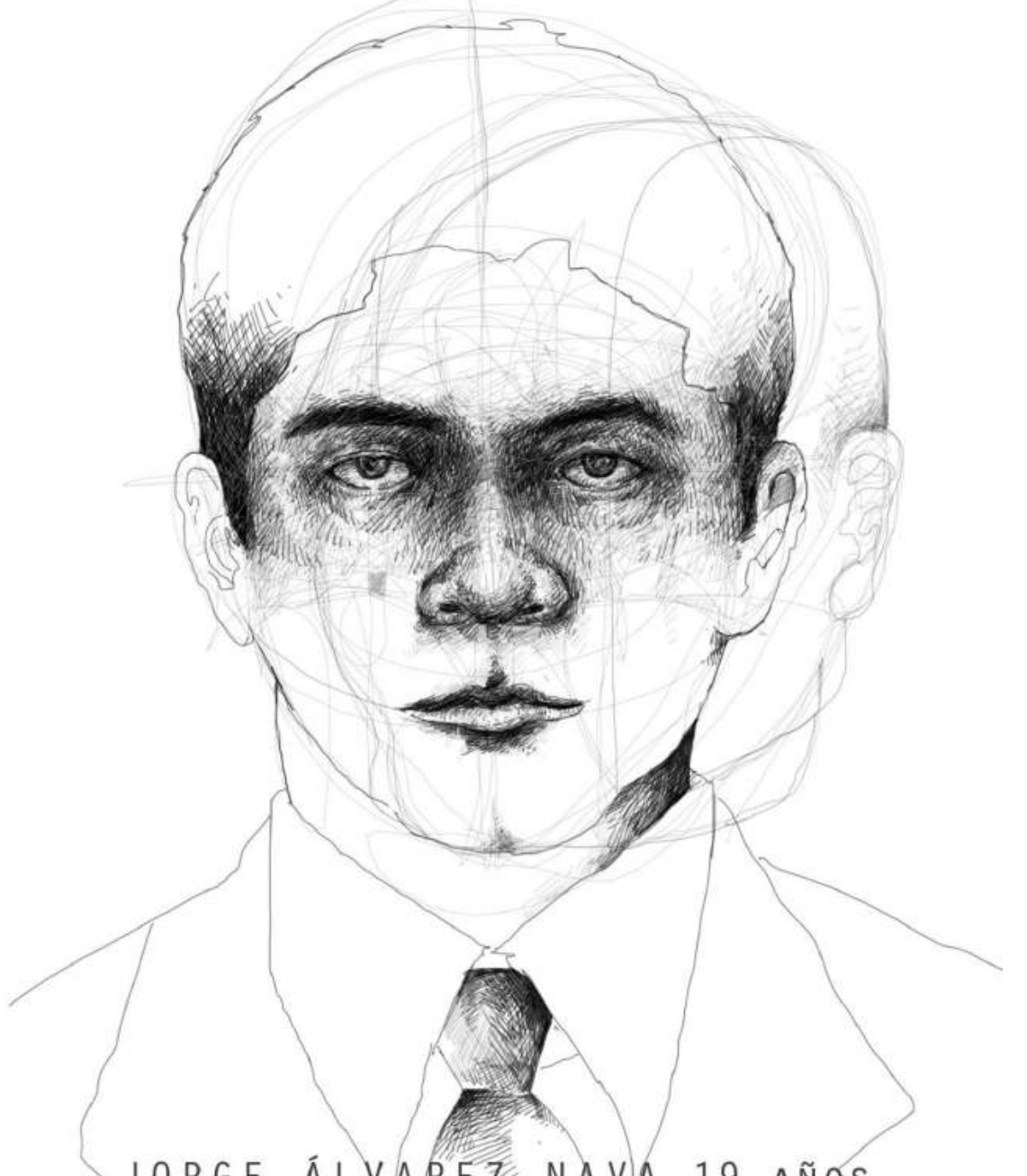

JORGE ÁLVAREZ NAVA 19 AÑOS

$$
\text { IVIVO! }
$$

- César Manuel Gahzález - Hernánde $z$

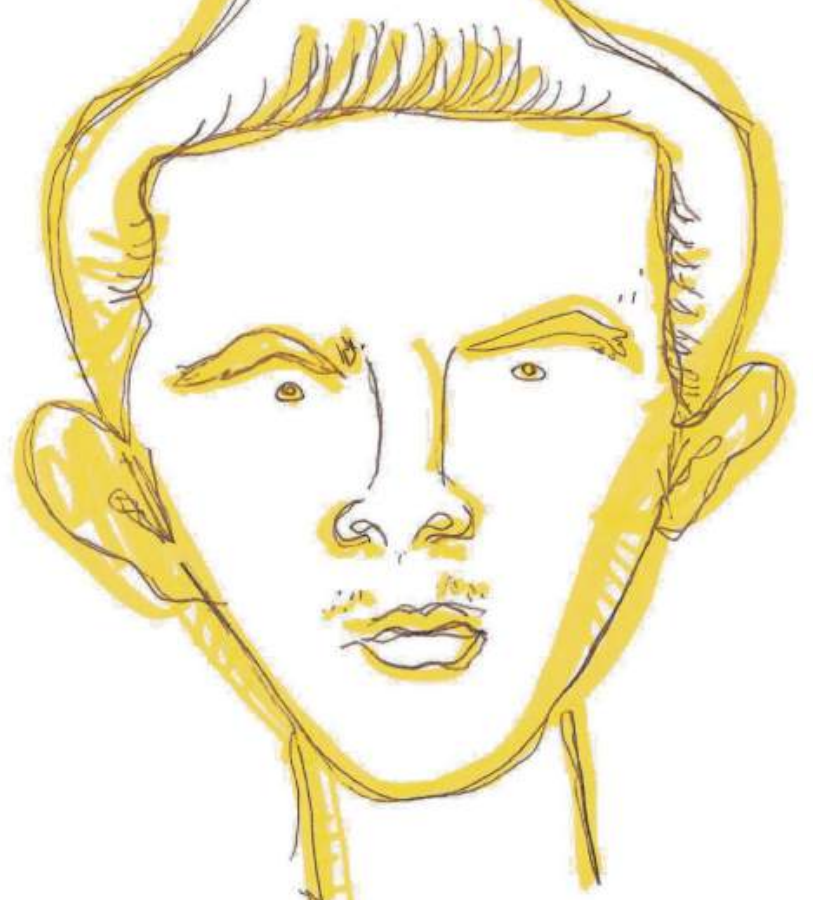

il

- Jovany Rodriages
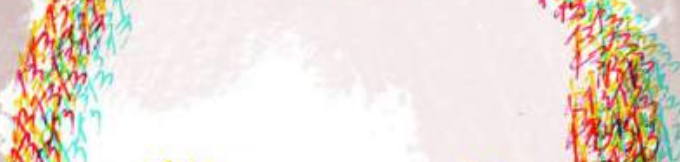

$x$. (2)

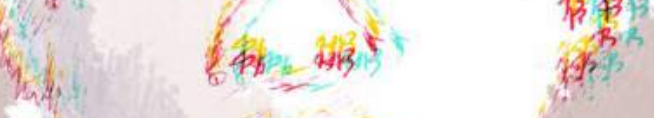
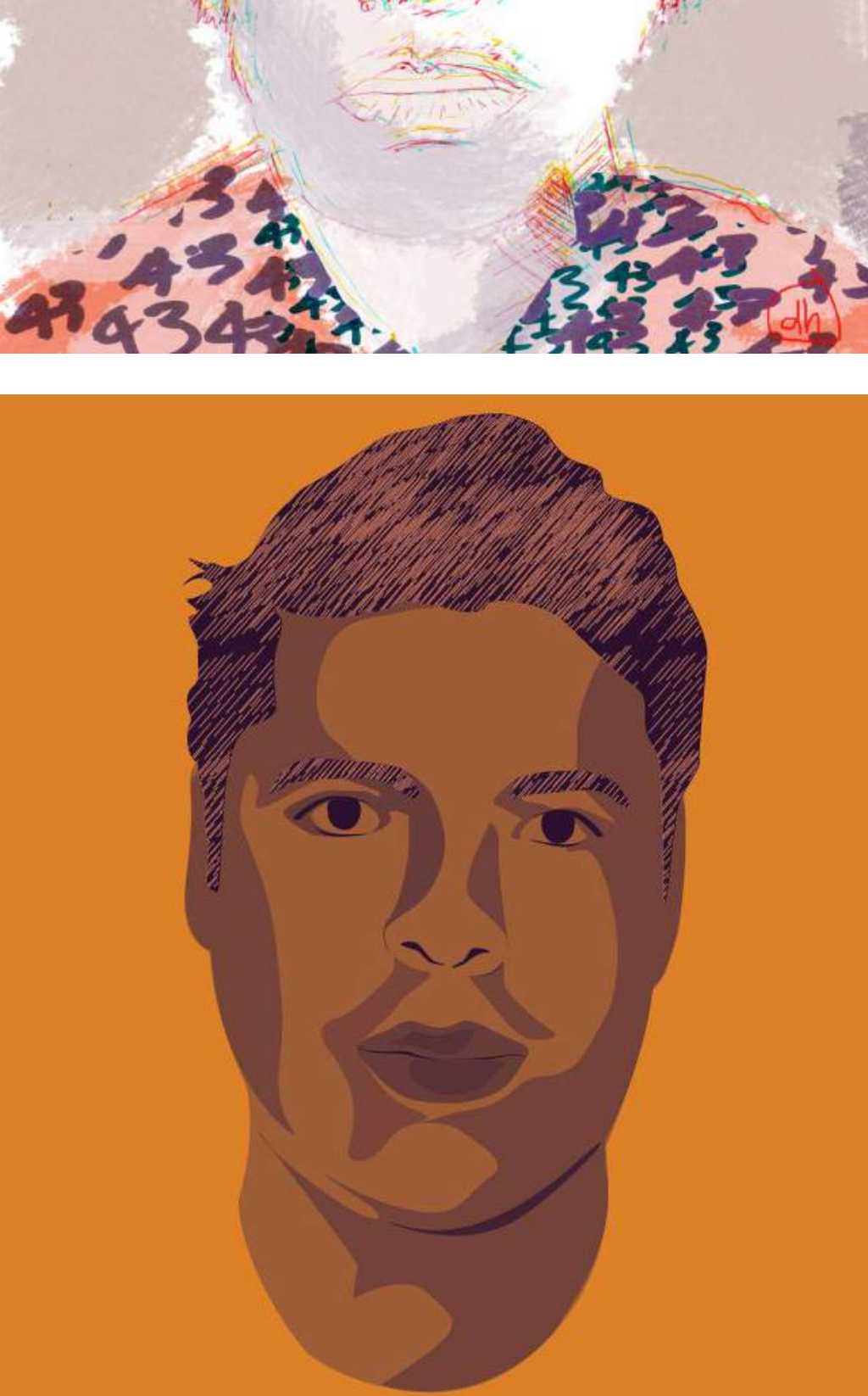

YO, REGINA COSS QUIERO SABER DÓNDE ESTA EMILANO ALEN GASPAR DE LA GRUZ 

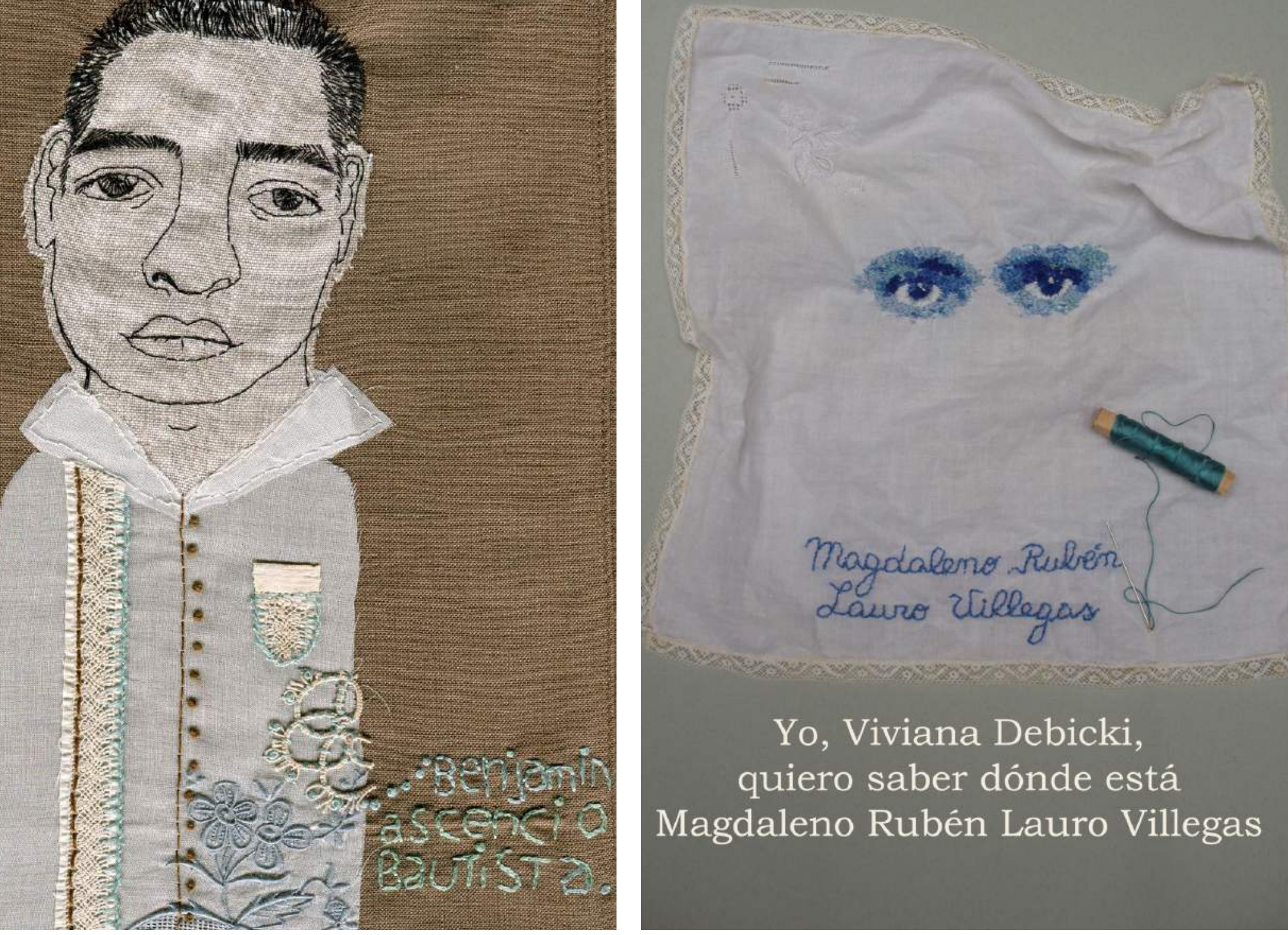

también el triunfo de facto de la impunidad. No saber qué pasó con ellos contribuye a que las causas estructurales detrás de este atentado sigan intactas.

No hay conclusiones esclarecedores, ni en el caso de Ayotzinapa ni en mi proyecto curatorial. En este artículo se ha hablado de responsabilidades en eventos que el actual gobierno de México niega rotundamente. De procesos individuales y sociales que llevan a la manifestación pública, o la creación artística, frente a la presencia de actos traumáticos o atentados de cualquier tipo a las libertades más básicas [sea en México, Colombia o Quebec]. Se habló de imágenes que duelen, de algoritmos que nunca encontrarán a las personas que están entrenadas para buscar, y apenas aciertan a dar un cierto nivel de confianza. Se habló de la curaduría como un proceso regenerativo, con base en la etimología de curare en latín: cuidar (Lehrer y Milton, 2006, p. 4; Fowle, 2008, p. 10). No se trata de exponer las heridas a que sigan siempre abiertas, aunque para que cierren hay que exponerlas al aire. Hay que dejarlas respirar.

\section{Referencias}

Animal Político. [2016a, 18 de julio]. Peña admite error por la Casa Blanca pero defiende haber actuado conforme a derecho. Animal Político, secc. Nacional. Consultado el 9 de agosto de 2016 en http:/ / www.animalpolitico. com/2016/07/pena-pide-perdon-por-casa-blanca-promulgaleyes-anticorrupcion/.

Animal Político. [2016b, 9 de agosto]. Angélica Rivera usa departamento de contratista en Miami, reporta The Guardian; Presidencia responde que no es de ella. Animal Político, secc. Nacional. Consultado el 9 de agosto de 2016 en http:/ / www.animalpolitico.com/2016/08/angelica-rivera-usadepartamento-miami-contratista-the-guardian/.

Associated Press. [2016a, 12 de julio]. Classmate of 43 missing Mexican students was tortured, report says. The Guardian. Consultado el 9 de agosto de 2016 en https:/ / www.theguardian.com/world/2016/jul/11/julio-cesarmondragon-missing-mexican-students-tortured.

Associated Press. [2016b, 20 de junio]. Nueve enfrentamientos entre la policía y los maestros en Oaxaca, al sur de México. New York Times en Español, secc. América Latina. Consultado el 9 de agosto de 2016 en http:/ / 

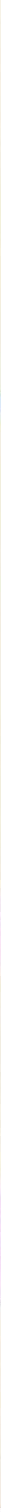

www.nytimes.com/es/2016/06/20/seis-muertos-enenfrentamiento-entre-la-policia-y-los-maestrosen-oaxaca-al-sur-demexico/.

Butler, S. R. y Lehrer, E. [2016). Introduction: Curatorial Dreaming. En Butler, S. R. y Lehrer, E. [Eds.]. Curatorial Dreams: Critics Imagine Exhibitions (pp. 3-23). Montreal: McGill-Queen's University Press.

CEREV. [2014]. Narcotrafic and the Art of Violence. Consultado el 9 de agosto del sitio de CEREV: http:/ / cerev.org/cerev/events/ narcotraffic-and-the-art-of-violence.

El Universal. [2013, 12 de junio]. Javier Sicilia se retira de la poesía: "el mundo no es digno de la palabra". El Universal, secc. Arte y Entretenimiento; consultado el 9 de agosto de 2016: http:/ / uww. eluniversal.com/arte-yentretenimiento/130612/javier-sicilia-seretira-dela-poesiael-mundo-noes-digno-de-la-palab.

Forbes. [2015, 7 de septiembre]. Expertos refutan "verdad histórica” sobre Ayotzinapa. Forbes México. Consultado el 9 de agosto de 2016 en http: / wuw.forbes.com.mx/ expertos-refutanverdad-historica-sobre-ayotzinapa/.

Fowle, K. [2007]. Who Cares? Understanding the Role of the Curator Today. En Rand, S., y Kouris, H. [Eds.]. Cautionary Tales: Critical Curating [pp. 10-19]. Nueva York: Apexart.
GIEl. [2015a]. Informe Ayotzinapa. Investigación y primeras conclusiones de las desapariciones y homicidios de los normalistas de Ayotzinapa. Resumen. México: Autor.

GEI. [2015b]. Informe Ayotzinapa Il. Avances y nuevas conclusiones sobre la investigación, búsqueda y atención a las víctimas. México: Autor.

Hirsch, M. [2008). The Generation of Postmemory. Poetics Today, 29[1], 103-128.

Huerta, D. [2014]. Ayotzinapa. Consultado el 9 de agosto de 2016 en https:/ / soundcloud.com/aviolus/ayotzinapa-david-huerta.

Huerta, E. [2001]. Mi país, joh mi país! La muchacha ebria y otros poemas en la voz de David Huerta [pista 11]. México: Fondo de Cultura Económica.

Knoll, A., y Wences, M. [2014, 30 de septiembre]. Mexican Police Accused of Brazen Attacks on Buses Carrying Students and Soccer Players. Vice News. Consultado el 9 de agosto de 2016 en https://news.vice.com/article/mexican-police-accused-of-brazenattacks-on-buses-carrying-students-and-soccer-players.

Lacy, S., y Riaño, P. [2006]. Medellín, Colombia: Reinhabiting Memory. Art Journal, 65[4], Winter, 96-112. 
Lehrer, E. y Mitton, C. E. [2006]. Introduction: Witness to Witnessing. En Lehrer, E., Milton, C. E., y Patterson, M. E. [Eds.]. Curating Difficult Knowledge. Violent Pasts in Public Places (pp. 1-19). New York: Palgrave MacMillan.

Lozano, R. (2015]. Level of Confidence. Consultado el 9 de agosto de 2016 en https: / vimeo.com/128678514.

Mastrogiovanni, F. (2014, 18 de noviembre). Caso Ayotzinapa. El Ejército participó en la desaparición de los normalistas: General Gallardo. Variopinto. Consultado el 9 de agosto de 2016 en http: / / unw.revistavariopinto.com/nota.php?id=4292\&rel=aldia\&titulo=pcaso-ayotzinapaelej-and-eacutercito-particip-and-oacuteen-ladesapariciand-oacuten-delos-normalistas-generalgallardo-p.

Milenio Digital. (2014, २2 de diciembre). Alcalde de Cocula, una pieza clave en caso Iguala. Milenio, secc. Policía. Consultado el 9 de agosto de 2016 en http: / / www.milenio.com/policia/ alcalde_Cocula_Guerrero-Cesar_Penaloza_Santana-caso_lgualadesaparecidos_O_431956986.html.

Najar, A. [2016, 21 de junio]. Las dudas sobre el enfrentamiento de policías y maestros que causó 8 muertos en Oaxaca, México. BBC, secc. Mundo. Consultado el 9 de agosto de 2016; http: / / umw.bbc. com/mundo/noticias-america-latina-36592794.

Ordaz, D. (2016, 9 de agosto). Angélica Rivera ocupa departamento en Miami, propiedad de potencial contratista del gobierno. The Guardian. Aristegui Noticias. Consultado el 9 de agosto de 2016 en http:/ / aristeguinoticias.com/0908/mexico/angelica-riveraocupa-departamentoen-miami-propiedad-de-potencialcontratista-det gobiernothe-guardian/.

Organización Editorial Mexicana. [2014, 28 de septiembre]. Dos balaceras dejan 6 muertos y 17 heridos en Iguala, Guerrero. La prensa, secc. México. Consultado el 9 de agosto de 2016 en http:/ / unw.oem.com.mx/laprensa/notas/n3552537.htm.

Pigeonutt, V. [2014, 28 de septiembre]. Identifican cuerpo desollado como normalista de Ayotzinapa. El universal, secc. Estados. Consultado el 9 de agosto de 2016 en http: / / archivo.eluniversal. com.mx/estados/2014/identifican-cuerpo-desollado-comonormalista-de-ayotzinapa-1041792.html.

Proceso. [2016, 13 de septiembre]. Experimento publicado por la revista Science refuta "verdad histórica" sobre Ayotzinapa. Proceso, secc. Nacional. Consultado el 9 de septiembre de 2016 en http:/ / unw.proceso.com.mx/454832/experimento-publicado-la-revistasciencerefuta-verdad-historica-ayotzinapa-video.

Red Polltica. [2014, 4 de noviembre). Perfil Abarca y Pineda, la 'narcopareja' que gobernó lguala. Red poltitica - El universal.com.mx Consultado el 9 de agosto de 2016 en http:/ / www.redpolitica.mx/ nacion/perfilabarca-ypinedalanarcopareja-que-goberno-iguala.

Rosales, N. [2014). Ayoztinapa, de David Huerta. Tierra adentro. Consultado el 9 de agosto de 2016 en http: / $/$ www. tierraadentro.cultura.gob.mx/ayotzinapa-de-david-huerta/.

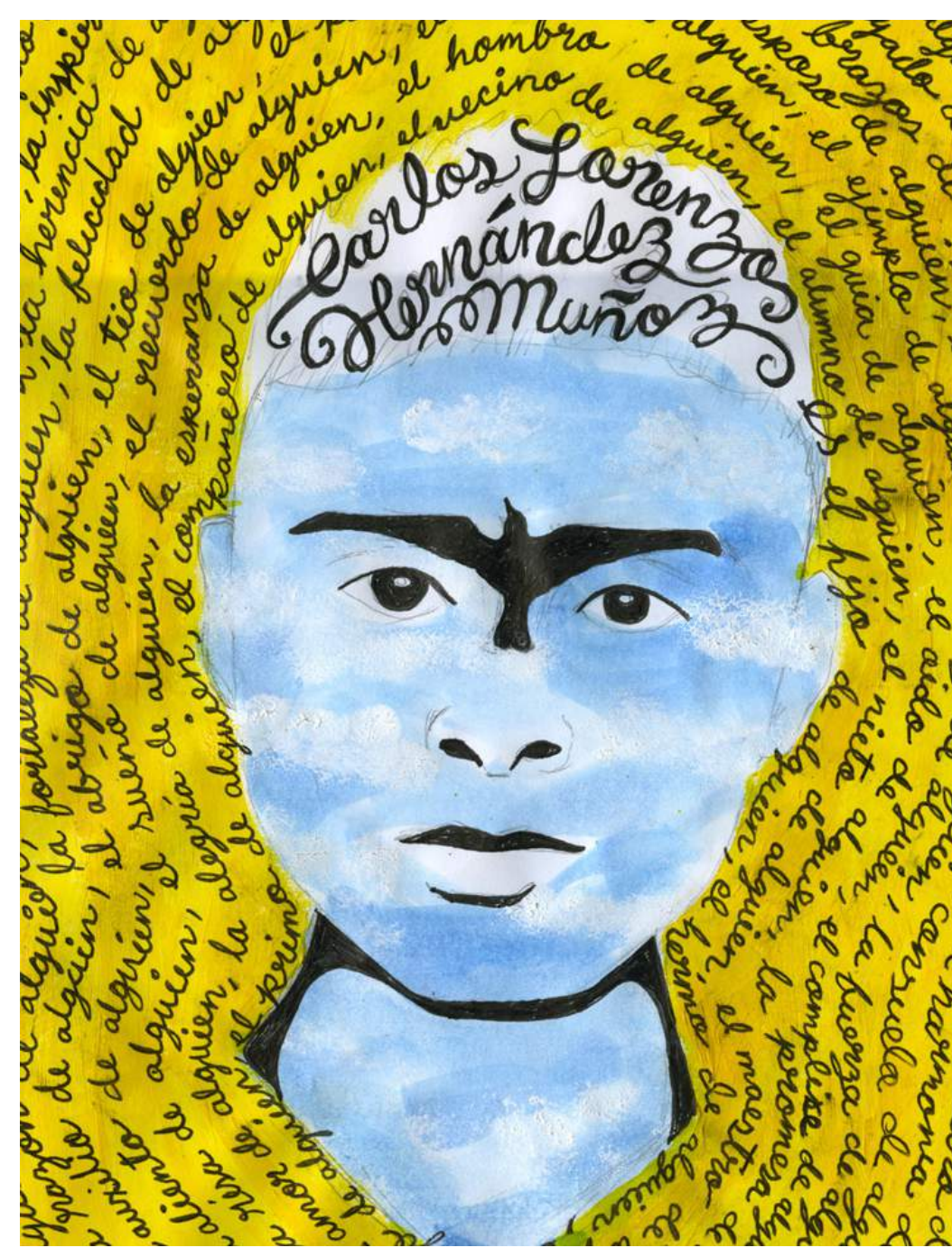

\section{Si Doriam González Parral} no estuviera desaparecido

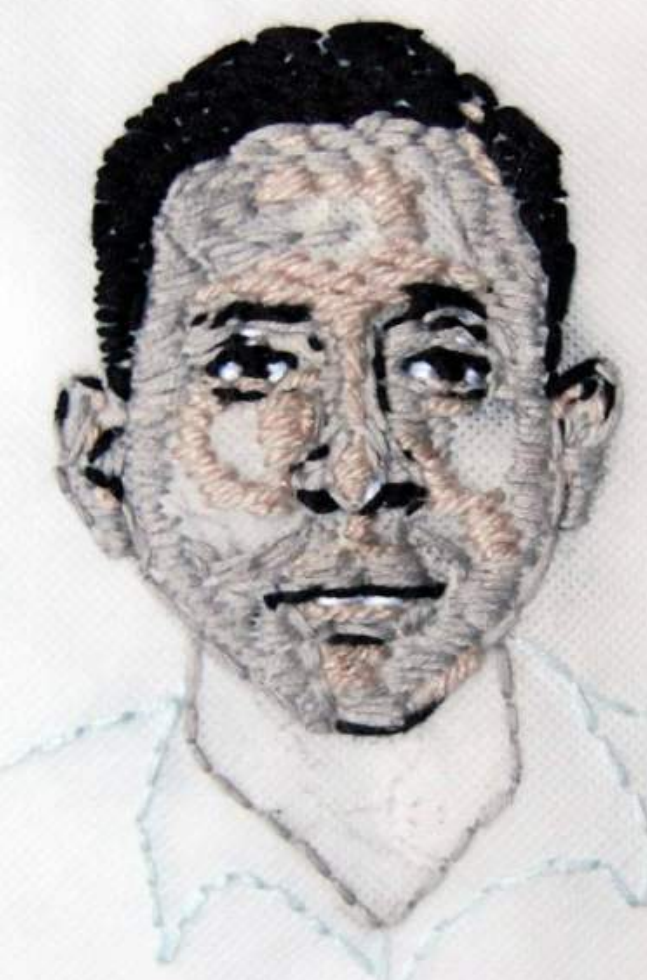

Valencia, S. [2010]. Capitalismo gore. Madrid: Melusina. 
